\title{
Genetic diversity and antimicrobial resistance among isolates of Escherichia coli 0157: H7 from feces and hides of super-shedders and low-shedding pen-mates in two commercial beef feedlots
}

\author{
Kim Stanford ${ }^{1 *}$, Chelsey A Agopsowicz ${ }^{1}$ and Tim A McAllister ${ }^{2}$
}

\begin{abstract}
Background: Cattle shedding at least $10^{4}$ CFU Escherichia coli O157:H7/g feces are described as super-shedders and have been shown to increase transmission of E. coli O157:H7 to other cattle in feedlots. This study investigated relationships among fecal isolates from super-shedders $(n=162)$, perineal hide swab isolates (PS) from super-shedders $(n=137)$ and fecal isolates from low-shedder $\left(<10^{4}\right.$ CFU/g feces) pen-mates $(n=496)$ using pulsed-field gel electrophoresis (PFGE). A subsample of these fecal isolates $(n=474)$ was tested for antimicrobial resistance. Isolates of E. coli O157:H7 were obtained from cattle in pens (avg. 181 head) at 2 commercial feedlots in southern Alberta with each steer sampled at entry to the feedlot and prior to slaughter.

Results: Only 1 steer maintained super-shedder status at both samplings, although approximately 30\% of super-shedders in sampling 1 had low-shedder status at sampling 2. A total of 85 restriction endonuclease digestion clusters (REPC; $90 \%$ or greater similarity) and 86 unique isolates (<90\% similarity) were detected, with the predominant REPC (30\% of isolates) being isolated from cattle in all feedlot pens, although it was not associated with shedding status (super- or low-shedder; $P=0.94$ ). Only $2 / 21$ super-shedders had fecal isolates in the same REPC at both samplings. Fecal and PS isolates from individual super-shedders generally belonged to different REPCs, although fecal isolates of E. coli O157:H7 from super- and low-shedders showed greater similarity $(P<0.001)$ than those from PS. For 77\% of super-shedders, PFGE profiles of super-shedder fecal and PS isolates were distinct from all low-shedder fecal isolates collected in the same pen. A low level of antimicrobial resistance (3.7\%) was detected and prevalence of antimicrobial resistance did not differ among super- and low-shedder isolates $(P=0.69)$, although all super-shedder isolates with antimicrobial resistance $(n=3)$ were resistant to multiple antimicrobials.

Conclusions: Super-shedders did not have increased antimicrobial resistance compared to low-shedder pen mates. Our data demonstrated that PFGE profiles of individual super-shedders varied over time and that only 1/162 steers remained a super-shedder at 2 samplings. In these two commercial feedlots, PFGE subtypes of E. coli O157:H7 from fecal isolates of super- and low-shedders were frequently different as were subtypes of fecal and perineal hide isolates from super-shedders.
\end{abstract}

Keywords: Super-shedder, E. coli O157:H7, Cattle, PFGE

\footnotetext{
* Correspondence: kim.stanford@gov.ab.ca

'Alberta Agriculture and Rural Development, Agriculture Centre, 100-5401 1st

Ave, S, Lethbridge, AB T1J 4 V6, Canada

Full list of author information is available at the end of the article
} 


\section{Background}

Cattle shedding at least $10^{4} \mathrm{CFU} / \mathrm{g}$ E. coli $\mathrm{O} 157$ in feces were first termed "super-shedders" by Matthews et al. [1], and the role of super-shedders in contamination of the food supply has been much investigated. As duration of super-shedding is unknown, Carlson et al. [2] proposed that persistent low-level shedders of E. coli O157: $\mathrm{H} 7$ were a greater food safety risk than were intermittent super-shedders. In contrast, $47 \%$ [3] to $>90 \%$ [4] of the shedding of E. coli O157:H7 within feedlot pens has been attributed to super-shedders, even though these animals are thought to represent $<10 \%$ of the cattle population $[4,5]$. As most previous studies of supershedders have evaluated a single point in time, it is also possible that many cattle are super-shedders for only a brief period. Accordingly, Robinson et al. [6] reported that within-animal variation of shedding E. coli $\mathrm{O} 157$ was greater than that among animals over time.

As the majority of cattle positive for E. coli $\mathrm{O} 157: \mathrm{H} 7$ shed $<100 \mathrm{CFU} / \mathrm{g}$ of feces [7], a super-shedder releasing up to $10^{9} \mathrm{CFU} / \mathrm{g}$ feces [3] even for short durations could represent a significant point source of environmental and possibly food contamination. In pens of 8 cattle, Cobbold et al. [8] observed that isolates of $E$. coli $\mathrm{O} 157$ were similar among super-shedders and pen mates based on pulsedfield gel electrophoresis (PFGE) analyses, while Stanford et al. [9] demonstrated that contaminating the perineum of a steer with feces containing $10^{6}$ CFU E. coli O157:H7 resulted in 7 of 8 steers in the pen acquiring and shedding this organism. In larger groups, presence of a supershedder in a load of 20 to 50 cattle during shipment to slaughter has increased carcass contamination with $E$. coli O157 [10,11]. However, it is not known if a similar level of transmission from super-shedders to pen mates occurs in commercial feedlot pens where 100 to 200 individuals may be housed.

Previously we reported that super-shedders increased the incidence of perineal swab (PS) contamination with E. coli $\mathrm{O} 157$ in pens of commercial cattle [3]. The objectives of the present study were to determine genetic relationships among subtypes of $E$. coli $\mathrm{O} 157: \mathrm{H} 7: 1$ ) shed in feces by super- and low-shedders $\left(<10^{4} \mathrm{CFU} / \mathrm{g}\right.$ feces $)$ in commercial feedlot pens; 2) shed in feces and detected on PS of super-shedders. Pulsed-field gel electrophoresis was used to characterize super-shedder subtypes of $E$. coli $\mathrm{O} 157: \mathrm{H7}$ as it has been used to evaluate genetic relationships and the transmission of E. coli O157 throughout the beef supply chain [12-14]. As antibiotic treatment can select for resistant bacteria and mutator alleles leading to increased virulence [15] and isolates from super-shedders may also have heightened virulence, antimicrobial resistance (AMR) profiles were also compared in isolates of E. coli O157:H7 from super- and low-shedder pen mates.

\section{Results and discussion}

\section{Occurrence of super-shedders}

Although 153 super-shedders were detected in sampling 1 (Table 1), only 1 steer was a super-shedder at both sampling dates. The number of super- and low- shedders markedly declined at the second sampling, likely due to the prevalence of $E$. coli $\mathrm{O} 157$ generally declining seasonally from summer to fall $[7,16]$ and after a month of acclimation of cattle within a feedlot [17] However, the proportion of super- as compared to low-shedders also declined at the second sampling, a result that may reflect the transition of super-shedders to low-shedder status as approximately $30 \%$ of low-shedders in the second sampling were super-shedders in sampling 1 . Of the 21 supershedders which were low-shedders in sampling 2, only 2 steers had fecal isolates of E. coli $\mathrm{O} 157: \mathrm{H} 7$ in the same REPC at both samplings. Transition in PFGE subtypes within super-shedders was likely due to both transmission of E. coli $\mathrm{O} 157: \mathrm{H} 7$ among animals and mutation events. Transmission was likely for 3 steers that had isolates within a prevalent REPC at the second sampling and isolates from 3 different REPC specific to super-shedders in sampling 1. Mutation or transfer of E. coli O157:H7 from other sources was likely for 5 steers where isolates in the second sampling were from REPC that were specific to sampling 2 and a single pen within a feedlot.

As only one steer was a super-shedder at both samplings, our results support the contention of Robinson et al. [6] that individual cattle are super-shedders for short periods and that levels of shedding vary widely among sampling time points. However, as former supershedders constituted a large proportion of the lowshedder individuals identified at the second sampling (i.e., 30\%), high-levels of shedding may also be associated with greater persistence of $E$. coli $\mathrm{O} 157$ within the gastro-intestinal tract $[4,8,18]$, although results of the current study demonstrate transition of fecal PFGE subtypes by super-shedders over time (Additional file 1, Additional file 2). With only 2 samples collected per steer at least 1 month apart, estimates of the duration of high-level shedding by super-shedders were not possible in this study, a factor that will be investigated in future studies through a more frequent sampling routine. Robinson et al. [6] used an intensive regime which involved sampling individuals every $3 \mathrm{~h}$, a protocol that would be almost impossible to implement under commercial feedlot conditions.

\section{Pulsed-field gel electrophoresis - most common profile} A level of $90 \%$ similarity ( $<3$ band differences) was chosen to define REPCs as PFGE profiles differing by one or two bands are considered to be highly related [19]. The REPC most frequently detected (REPC A) was also the only PFGE profile that was present in all pens at 
Table 1 Pens of cattle sampled in Alberta Canada in 2007 with 1 fecal grab sample and 1 hide swab collected per steer at each sampling and PFGE performed on samples positive for $E$. coli 0157:H7

\begin{tabular}{|c|c|c|c|c|c|c|c|c|c|c|c|c|}
\hline Feedlot & & & & A & & & & & & & & Total \\
\hline Pen & 1 & 2 & 3 & 4 & 5 & 6 & 7 & 1 & 2 & 3 & 4 & \\
\hline cattle (n) & 153 & 152 & 153 & 253 & 258 & 155 & 233 & 151 & 235 & 138 & 106 & 1987 \\
\hline Sample 1 date & May 22 & Jun 4 & Jul 20 & Jul 27 & Sep 26 & Oct 9 & Oct 23 & Jul 6 & Jul 12 & Aug 10 & Aug 30 & \\
\hline SS fecal isolates (n) & 2 & 36 & 12 & 19 & 7 & 3 & 0 & $19^{x}$ & 44 & 10 & 1 & 153 \\
\hline SS perineal swabs (n) & 2 & 30 & 11 & 17 & 3 & 3 & 0 & 17 & 40 & 7 & 1 & 131 \\
\hline LS fecal isolates (n) & 13 & 37 & 100 & 54 & 24 & 2 & 1 & 36 & 107 & 20 & 31 & 425 \\
\hline Sample 2 date & Sep 24 & Sep 6 & Oct 3 & Oct 17 & Dec 10 & Nov 29 & Dec 6 & Sep 28 & Sep 28 & Nov 14 & Nov 27 & \\
\hline SS fecal isolates (n) & 1 & 0 & 0 & 0 & 0 & 0 & 0 & $8^{x}$ & 0 & 0 & 0 & 9 \\
\hline SS perineal swabs (n) & 0 & 0 & 0 & 0 & 0 & 0 & 0 & 6 & 0 & 0 & 0 & 6 \\
\hline LS fecal isolates (n) & 3 & 10 & 0 & 2 & 3 & 0 & 1 & 40 & 9 & 3 & 0 & 71 \\
\hline $\begin{array}{l}\text { LS fecal isolates from } \\
\text { former SS }(n)\end{array}$ & 0 & 1 & 0 & 2 & 2 & 0 & 0 & 7 & 9 & 0 & 0 & 21 \\
\hline $\begin{array}{l}\text { Total isolates tested } \\
\text { by PFGE }(n)\end{array}$ & 21 & 113 & 123 & 92 & 37 & 8 & 2 & 126 & 200 & 40 & 33 & 795 \\
\hline Total REPC (n) & 1 & 12 & 14 & 14 & 6 & 1 & 1 & 20 & 13 & 6 & 6 & $85^{y}$ \\
\hline Total unique isolates (n) & 8 & 33 & 11 & 14 & 12 & 6 & 0 & 13 & 17 & 8 & 11 & $86^{y}$ \\
\hline $\begin{array}{l}\text { SS fecal \& SS perineal } \\
\text { swab in same REPC (n) }\end{array}$ & 1 & 1 & 0 & 0 & 0 & 0 & $N A^{z}$ & 0 & 0 & 0 & 0 & 2 \\
\hline
\end{tabular}

Numbers of super-shedders (SS) ${ }^{\mathrm{v}}$ and low- shedders (LS) ${ }^{\mathrm{w}}$ within pens. Numbers of, restriction endonuclease digestion clusters (REPC, $90 \%$ or greater similarity) and unique isolates ( $<90 \%$ similarity) within and across pens.

v'Super-shedder, shedding at least $10^{4} \mathrm{CFU}$ E. coli O157:H7/g feces.

wLow-shedder, shedding $<10^{4}$ CFU E. coli O157:H7/g feces.

${ }^{x}$ One steer was a super-shedder at both samplings.

${ }^{\mathrm{y}}$ Total comparing all isolates across pens.

${ }^{\mathrm{z}} \mathrm{NA}$, not applicable, no super-shedders in pen.

Table 2 Numbers of super-shedder (SS) ${ }^{v}$ and low-shedder (LS) ${ }^{\mathrm{w}}$ isolates from both samplings sharing restriction endonuclease digestion pattern clusters (REPC, $90 \%$ or greater similarity) and description of most prevalent REPC, REPC A by feedlot and pen

\begin{tabular}{|c|c|c|c|c|c|c|c|c|c|}
\hline \multirow[b]{2}{*}{ Feedlot } & \multirow[b]{2}{*}{ Pen } & \multicolumn{4}{|c|}{ All REPC ${ }^{x}$} & \multicolumn{4}{|c|}{ REPC A only } \\
\hline & & No.SS & No.LS & $\begin{array}{l}\text { No. SS sharing } \\
\text { REPC with LS (\%) }\end{array}$ & $\begin{array}{l}\text { No. SS in SS } \\
\text { only REPC (\%) }\end{array}$ & No. isolates & No, SS fecal & No. SS hide & No. LS fecal \\
\hline \multirow[t]{7}{*}{$\mathrm{A}$} & $1^{*}$ & 3 & 16 & $1(33)$ & $2(67)$ & 15 & 1 & 1 & 13 \\
\hline & $2^{*}$ & 36 & 47 & $12(33)$ & $24(67)$ & 41 & 12 & 6 & $23^{y}$ \\
\hline & 3 & 12 & 100 & $11(92)$ & $1(8)$ & 5 & 4 & 1 & 0 \\
\hline & 4 & 19 & 56 & $0(0)$ & $19(100)$ & 11 & 9 & 2 & 0 \\
\hline & 5 & 7 & 27 & $0(0)$ & $7(100)$ & 4 & 4 & 0 & 0 \\
\hline & 6 & 3 & 2 & $0(0)$ & $3(100)$ & 1 & 1 & 0 & 0 \\
\hline & 7 & 0 & 1 & $N A^{z}$ & NA & 2 & 0 & 0 & 2 \\
\hline \multirow[t]{4}{*}{$B$} & 1 & 27 & 76 & $4(15)$ & $23(85)$ & 12 & $12^{y}$ & 0 & 0 \\
\hline & $2^{*}$ & 44 & 116 & $9(20)$ & $35(80)$ & 120 & 9 & 10 & $101^{y}$ \\
\hline & $3^{*}$ & 10 & 23 & $1(10)$ & $9(90)$ & 19 & 1 & 0 & 18 \\
\hline & 4 & 1 & 31 & $0(0)$ & $1(100)$ & 5 & 0 & 0 & 5 \\
\hline Total & & 162 & 496 & $38(23)$ & $124(77)$ & 235 & 53 & 20 & 162 \\
\hline
\end{tabular}

Pens where SS and LS isolates belonged to REPC A are marked by *, percentages are bracketed.

vSuper-shedder, shedding at least $10^{4}$ CFU E. coli O157:H7/g feces.

wLow-shedder, shedding $<10^{4}$ CFU E. coli O157:H7/g feces.

${ }^{\times}$All REPC, number of super-shedders based on fecal isolates, super-shedder fecal and hide swab isolates included in REPC shared with low-shedders.

$y$ Includes isolates from the second sampling.

${ }^{\mathrm{z}} \mathrm{NA}$, not applicable, no super-shedders in pen. 
both feedlots (Table 2), likely representing an E. coli O157:H7 subtype that is common to feedlots within the sampling area. In sampling 1, 28\% of isolates belonged to REPC A, with $34 \%$ of isolates in REPC A at sampling 2. Within pens, membership in REPC A was not homogeneous and in 2 pens this PFGE profile was confined to low-shedders, while in 4 pens this PFGE profile was found only in super-shedders. As REPC A was not related to E. coli $\mathrm{O} 157: \mathrm{H} 7$ shedding status of the cattle $(P=0.94$; Table 3$)$, the abundance of isolates from this REPC is likely indicative of the fitness of this E. coli O157:H7 in the gastrointestinal tract or feedlot environment. Accordingly, Carlson et al. [2] determined that persistence and dominance of E. coli $\mathrm{O} 157: \mathrm{H} 7$ strains isolated from feedlot cattle was influenced by genotype and possibly related to the degree of adherence to intestinal epithelial cells

As REPC A was of similar prevalence in both sampling 1 and $2(P=0.18$; Table 3$)$, there was no evidence of a transition over time to a single dominant subtype of $E$. coli $\mathrm{O} 157$ which would account for the majority of isolates, likely due to the wide diversity of PFGE subtypes in calves entering the feedlot [14]. Considering all PFGE subtypes, genetic diversity tended to increase slightly from sampling 1 (average of 4 isolates per subtype) to sampling 2 (average of 3 isolates per subtype), although any change in diversity was mostly likely a reflection of the disparity in numbers of isolates of E. coli O157:H7 collected (709 isolates in sampling 1 as compared to 86 in sampling 2).

\section{Comparison of super-shedder hide swab and fecal grab isolates}

Due to the volume of isolates collected and the laborious nature of PFGE, only one isolate was analysed per sample type which may have under-estimated the genetic diversity of $E$. coli $\mathrm{O} 157: \mathrm{H} 7$ compared to analysis of multiple isolates [20], although analysis of a single isolate is generally indicative of the dominant strain [21,22]. Consequently, the lack of congruity between simultaneously-collected fecal and PS isolates from individual super-shedders was surprising, as only 2 super-

Table 3 Relationships among super-shedder status (yes/ no), sampling (1 vs 2 ) and membership in the most prevalent restriction endonuclease digestion pattern cluster, REPC A , as compared to all other REPC for fecal isolates of $E$. coli 0157:H7 collected in Alberta Canada in 2007 from generalized linear mixed model analysis ${ }^{2}$

\begin{tabular}{llll}
\hline Variable & Odds Ratio & $\mathbf{9 5 \%}$ C.I. & Significance \\
\hline Sampling & 1.27 & $0.68-4.37$ & $P=0.18$ \\
\hline Super-shedder & 0.98 & $0.64-1.51$ & $P=0.94$
\end{tabular}

${ }^{\mathrm{z}}$ Pen as random effect with covariance parameter estimate $=1.48$ and standard error $=0.83$. shedder steers had PS and fecal isolates in the same REPC (Table 1).

Most previous studies have used PFGE to characterize either hide or fecal isolates of E. coli O157:H7 [14,2224]. Avery et al. [12] found some commonality of PFGE subtypes from E. coli O157:H7 isolated from the hide and feces of the same animal, but only sampled 5 cattle. Arthur et al. [25] found similarities as 9 hide and 22 fecal PFGE profiles for E. coli O157:H7 from a single feedlot belonged to only 2 REPC. In contrast, from 795 E. coli $\mathrm{O} 157: \mathrm{H7}$ isolates in the present study, a total of 85 REPCs and 86 unique isolates were detected (Table 1). Genetic diversity of E. coli O157:H7 varies widely by location, ranging from $100 \%$ of isolates in a single REPC [26], to the heightened diversity noted in our study and that of Sargeant et al. [14]. Similar to the present study, Childs et al. [27] found only occasional commonality among PFGE profiles of $E$. coli $\mathrm{O} 157: \mathrm{H} 7$ isolates onfarm collected from hides and those collected from the colon post-harvest.

Overall genetic diversity of super-shedder PS isolates across pens was high and PS isolates as a group were not more similar than E. coli $\mathrm{O} 157: \mathrm{H} 7$ isolates overall $(P=0.77)$, although within the majority of pens, PS isolates had more similar PFGE profiles than all isolates from that pen $(P<0.01$; Table 4$)$. In contrast, all superand low-shedder fecal isolates across pens had more similar PFGE profiles compared to all isolates $(P<0.001)$, demonstrating a greater degree of similarity in fecal as compared to PS isolates. Genetic variation among fecal grab and PS isolates collected from the same animal may reflect the contamination of hides by E. coli $\mathrm{O} 157: \mathrm{H} 7$ originating from the feedlot environment or other cattle within the pen [27]. Escherichia coli O157:H7 on the hide would also be subjected to additional stresses such as irradiation, elevated temperatures and desiccation, all of which have been shown to increase phylogenetic diversity of E. coli O157:H7 [28]. As well, if cattle are carrying multiple strains of $E$. coli O157:H7 within the gastro-intestinal tract certain strains might preferentially survive on hides due to difference in environmental fitness among isolates [29].

\section{Transmission of E. coli 0157:H7 from super-shedders to pen mates}

In all feedlot pens monitored, PFGE profiles of fecal isolates from low-shedders were more similar $(P<0.05)$ than those from E. coli O157:H7 isolates overall (Table 4) and in 3 of 6 pens with sufficient isolates for comparison, were more similar than those of super-shedder fecal isolates. Sharing of PFGE profiles between low- and super-shedder isolates collected in the same pen was uncommon and $77 \%$ of super-shedder isolates were distinct from low-shedders within the same pen (Table 2). For 4/ 
Table 4 Average group similarity of PFGE profiles by source of isolates compared by bootstrapping analyses $(n=1000)$ to the similarity of PFGE profiles for all isolates within a pen or across all pens

\begin{tabular}{|c|c|c|c|c|c|c|c|}
\hline Feedlot & Pen & $\begin{array}{l}\text { SS fecal PFGE } \\
\text { similarity (\%) }\end{array}$ & $\begin{array}{l}\text { Signif }{ }^{y} \text { of } \\
\text { group }\end{array}$ & $\begin{array}{l}\text { PS PFGE } \\
\text { similarity (\%) }\end{array}$ & $\begin{array}{l}\text { Signif of } \\
\text { group }\end{array}$ & $\begin{array}{l}\text { LS fecal PFGE } \\
\text { similarity (\%) }\end{array}$ & $\begin{array}{l}\text { Signif of } \\
\text { group }\end{array}$ \\
\hline \multicolumn{8}{|c|}{ Within pen } \\
\hline \multirow[t]{7}{*}{ A } & 1 & 57.92 & NS & 59.94 & NS & 89.82 & $* * *$ \\
\hline & 2 & 62.18 & NS & 60.75 & NS & 72.80 & $* * *$ \\
\hline & 3 & 78.23 & $* * *$ & 58.62 & $* * *$ & 67.04 & $* * *$ \\
\hline & 4 & 85.92 & $* * *$ & 68.59 & $* * *$ & 72.70 & $* * *$ \\
\hline & 5 & 68.61 & $* *$ & 87.03 & $* * *$ & 70.97 & $* * *$ \\
\hline & 6 & 60.08 & NS & 73.49 & $* *$ & 85.72 & $*$ \\
\hline & 7 & $\mathrm{IN}^{\mathrm{Z}}$ & IN & IN & IN & IN & IN \\
\hline \multirow[t]{4}{*}{$B$} & 1 & 69.72 & $* * *$ & 64.81 & $* * *$ & 66.19 & $* * *$ \\
\hline & 2 & 73.98 & $* * *$ & 72.13 & $* * *$ & 86.69 & $* * *$ \\
\hline & 3 & 77.66 & $* * *$ & 68.89 & $* * *$ & 88.99 & $* * *$ \\
\hline & 4 & IN & IN & IN & IN & IN & IN \\
\hline Across all pens & & 64.80 & $* * *$ & 61.21 & NS & 64.91 & $* * *$ \\
\hline
\end{tabular}

SS fecal = fecal sample from super shedder (at least $10^{4} \mathrm{CFU} / \mathrm{g}$ feces); LS = fecal sample from low shedder $\left(<10^{4} \mathrm{CFU} / \mathrm{g}\right.$ feces), PS $=$ Perineal hide swab.

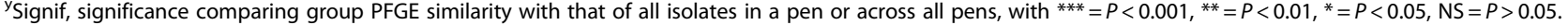
$\mathrm{z}_{\mathrm{IN}}$, insufficient number of isolates for comparison, a minimum of 2 PFGE profiles per group are required.

11 pens, PFGE profiles of all low-shedder isolates were distinct from both fecal and PS isolates of super-shedders, while 4/11 pens shared PFGE profiles of low- and super-shedder isolates only in REPC A.

Pen 2 of feedlot $B$ had both the highest number of super-shedders detected $(n=44)$ and the highest number of steers positive for E. coli O157:H7 (n=200). Thirty-four of the super-shedders had fecal isolates in REPCs unique to super-shedders with the remaining super-shedder isolates belonging to REPC A which colonized cattle regardless of shedding status. Similarly, pen 2 from feedlot A had a total of 36 super shedders, but 24 super-shedder fecal isolates belonged to REPCs unique to super- shedders and the remaining 12 belonged to REPC A. Pen 1 of feedlot B was notable as 8 of 9 super-shedders detected in the second sampling were housed in this pen (Table 1), but only 4/27 fecal isolates from super-shedders belonged to a REPC which also contained low-shedders (Table 2). In contrast to previously described pens, Pen 3 in feedlot A showed closer relationships among super-shedder and low-shedder PFGE profiles, as 11/12 super-shedder fecal isolates were in REPCs which also contained $46 \%$ of lowshedder fecal isolates.

In all pens of cattle with $>5$ super-shedders, REPC exclusive to super-shedders were noted. In contrast, superand low-shedders did not share PFGE subtypes of $E$. coli O157:H7 in all pens of cattle evaluated. As multiple super-shedders shared PFGE subtypes, it is possible that transmission of these subtypes from an initial supershedder resulted in a gradual conversion of pen mates to super-shedding status. In pens where super- and lowshedders shared PFGE subtypes, it is possible that super- shedders were transmitting these subtypes to pen-mates. Due to the limited sharing of PFGE subtypes by superand low-shedders, these results would agree with those of Dodd et al. [13] where high and low-shedding cattle in truck-loads at slaughter shared identical PFGE subtypes in feces less than $25 \%$ of the time. The high degree of similarity in PFGE subtypes of super- and lowshedder E. coli O157:H7 isolates reported by Cobbold et al. [8] is likely a reflection of less diversity of $E$. coli O157:H7 in pens of 8 animals compared to that noted in the commercial feedlot pens of the present study.

If high-level shedding is transient in accord with Robinson et al. [6], certain REPC might be specific to super-shedders with low-shedders in these REPC either former or future super-shedders. Conversely, as hide contamination is of crucial importance in transmission of $E$. coli O157:H7 among pen mates [9,30], subtypes of E. coli O157:H7 carried on hides of super-shedders might be more critical for dissemination of the organism within a feedlot pen than those within feces. Accordingly, in our previous study and source of isolates for the current study [3], presence of super-shedders within a feedlot pen increased incidence of contamination of PS with E. coli $\mathrm{O} 157: \mathrm{H} 7$, although incidence or level of fecal shedding within pens was not uniformly impacted. Analysis of PFGE subtypes of PS from low-shedders would have helped to clarify the role of super-shedders in transmission of E. coli O157:H7 in commercial feedlot pens, but unfortuntately was not possible in the present study due to budget restraints. Transmission of $E$. coli O157:H7 within commercial feedlot pens is undoubtedly complex and additional study will be required to 
confirm the relationship between fecal and hide contamination and if specific REPC are associated with supershedders.

\section{Anti-microbial resistance and PFGE profiles of $E$. coli 0157:H7}

Anti-microbial resistance of E. coli $\mathrm{O} 157: \mathrm{H} 7$ isolates was low (3.7\%; Table 5) and did not differ in frequency among low- and super-shedders ( $P=0.69$; Table 6$)$. The 3 supershedder isolates with AMR all showed multi-drug resistance in contrast to the low-shedders where resistance to tetracycline predominated (10/14 resistant isolates). Qualitatively, no relationships among AMR and PFGE profiles were evident as resistant isolates were spread across REPC and unique isolates (data not shown).

Resistance in the current study was lower than that reported for E. coli $\mathrm{O} 157$ by Rao et al. [31] in a survey of 21 Alberta feedlots, although those authors found higher levels of AMR in newly arrived cattle during the spring as compared to pre-slaughter. In accord with Alexander et al. [32], the most common AMR in the present study was to tetracycline. Antimicrobial resistance in the current study would be consistent with that for $93 \mathrm{E}$. coli O157:H7 isolates previously collected from feedlot B [33] where only 3 isolates exhibited AMR to either tetracycline or chloramphenicol, and one isolate demonstrated multi-drug resistance to tetracycline, amoxicillin/
Table 6 Relationships among super-shedder status (yes/ no), sampling ( 1 vs 2 ) and resistance to any antimicrobial evaluated ${ }^{y}$ for fecal isolates of $E$. coli 0157:H7 collected in Alberta Canada in 2007 from generalized linear mixed model analysis ${ }^{z}$

\begin{tabular}{llll}
\hline Variable & Odds Ratio & $\mathbf{9 5 \% ~ C . I . ~}$ & Significance \\
\hline Sampling & 1.51 & $0.48-4.78$ & $P>0.48$ \\
\hline Super-shedder & 0.94 & $0.31-2.91$ & $P>0.69$
\end{tabular}

${ }^{y}$ Resistance detected for $17 / 474$ isolates for antimicrobials including ampicillin, neomycin, streptomycin, sulfasoxazole, sulfamethoxazole/trimethroprim and tetracycline.

${ }^{\mathrm{z}}$ Pen as random effect, covariance parameter estimate $=1.82$, with standard error $=2.16$.

clavulanic acid and ampicillin. Reasons for the low level of AMR in the present study are not known as antimicrobial use at feedlots A and B was similar to that of other feedlots in Alberta.

Multi-drug resistance has been linked to the presence of plasmids carrying multiple resistance determinants [34] and the presence of these plasmids has been demonstrated to confer fitness to environmental challenges such as acid tolerance and nutrient scarcity along with resistance to antimicrobials [35]. Accordingly, enterotoxigenic strains of $E$. coli have an increased prevalence of plasmid-mediated genes for antimicrobial resistance [36], although a relationship between virulence and AMR in E. coli O157:H7 has not been fully

Table 5 Numbers and profiles of antibiotic resistance (AMR) of E. coli 0157:H7 isolated from feces collected in Alberta, Canada in 2007 and number of isolates susceptible to all antibiotics (SUS) by feedlot and pen for super-shedders (SS) and low-shedders (LS) ${ }^{y}$ of E. coli 0157:H7

\begin{tabular}{|c|c|c|c|c|c|c|}
\hline Feedlot & Pen & $\begin{array}{l}\text { No. of resistant } \\
\text { SS isolates (\%) }\end{array}$ & Resistance to $^{z}$ & $\begin{array}{l}\text { No. of resistant } \\
\text { LS isolates (\%) }\end{array}$ & Resistance to & $\begin{array}{l}\text { Total } \\
\text { No. SUS }\end{array}$ \\
\hline \multirow[t]{7}{*}{$\bar{A}$} & 1 & $0(0)$ & ND & $2(12)$ & $\begin{array}{l}\text { tetracycline, sulfasoxazole, } \\
\text { neomycin, streptomycin, } \\
\text { tetracycline }\end{array}$ & 19 \\
\hline & 2 & $1(3)$ & $\begin{array}{l}\text { ampicillin, sulfasoxazole, } \\
\text { streptomycin, tetracycline }\end{array}$ & $2(6)$ & $\begin{array}{l}\text { tetracycline, sulfasoxazole, } \\
\text { streptomycin, sulfamethoxazole/ } \\
\text { trimethroprim }\end{array}$ & 71 \\
\hline & 3 & $0(0)$ & ND & $1(4)$ & tetracycline & 35 \\
\hline & 4 & $2(11)$ & $\begin{array}{l}\text { ceftazidime, streptomycin, } \\
\text { sulfasoxazole, sulfamethoxazole/ } \\
\text { trimethro-prim }\end{array}$ & $2(9)$ & $\begin{array}{l}\text { tetracycline, tetracycline, } \\
\text { streptomycin }\end{array}$ & 41 \\
\hline & 5 & $0(0)$ & ND & $1(3)$ & $\begin{array}{l}\text { sulfasoxazole, streptomycin, } \\
\text { tetracycline }\end{array}$ & 46 \\
\hline & 6 & $0(0)$ & ND & $1(3)$ & tetracycline & 34 \\
\hline & 7 & $0(0)$ & ND & $0(0)$ & ND & 1 \\
\hline \multirow[t]{4}{*}{$B$} & 1 & $0(0)$ & ND & $3(6)$ & tetracycline & 78 \\
\hline & 2 & $0(0)$ & ND & $0(0)$ & ND & 94 \\
\hline & 3 & $0(0)$ & ND & $1(6)$ & tetracycline & 26 \\
\hline & 4 & $0(0)$ & ND & $1(9)$ & tetracyline & 12 \\
\hline Total & & $3(2)$ & & $14(5)$ & & 457 \\
\hline
\end{tabular}

${ }^{\mathrm{x}}$ Super-shedder, shedding at least $10^{4} \mathrm{CFU}$ E. coli O157:H7/g feces.

'Low-shedder, shedding $<10^{4}$ CFU E. coli 0157:H7/g feces.

${ }^{\mathrm{z}}$ Antibiotic resistance: No resistance to enrofloxacin, amoxicillin/clauvanate or cetiofur was detected. 
established. That all fecal isolates from super-shedders of E. coli O157:H7 with AMR demonstrated multi-drug resistance is intriguing, but confirming a relationship between presence of multiple drug resistance and heightened colonization with or shedding of $E$. coli O157:H7 would require additional study at locations with a higher incidence of AMR.

\section{Conclusions}

Results of this study suggest that feedlot cattle do not remain super-shedders for extended periods, as only $1 / 162$ steers was a super-shedder in 2 sampling periods that were at least 6 weeks apart. Approximately 30\% of lowshedders in sampling 2 were super-shedders in sampling 1 , indicating that high-level shedding may be related to increased persistence of E. coli $\mathrm{O} 157: \mathrm{H} 7$ in the gastrointestinal tract. Accordingly, $15.4 \%$ of low-shedders shed E. coli $\mathrm{O} 157: \mathrm{H} 7$ in both sampling periods compared to $33.5 \%$ of super-shedders (data not shown). Based on PFGE analyses, diversity of hide and fecal isolates from individual super-shedders was high as only $2 / 162$ supershedder steers had hide and fecal isolates in the same REPC. The most common REPC, REPC A, was not related to shedding status (super- or low-shedder) of cattle and was also the most common REPC in both samplings, possibly reflecting increased fitness of this subtype of E. coli O157:H7. Overall, 77\% of super-shedder isolates (fecal and PS) were distinct from low-shedder fecal isolates in the same pen. If isolates belonging to REPC A were excluded, $<10 \%$ of super-shedders shared PFGE profiles with low-shedders in the same pen. Consequently, transmission of E. coli $\mathrm{O} 157: \mathrm{H} 7$ from supershedders to low-shedder pen mates may be limited.

\section{Methods}

\section{Collection of samples}

Isolates were those collected in 2007 in the study of Stephens et al. [3] (excluding samples from 1 pen lost to a freezer malfunction) and were obtained from a total of 11 pens in two commercial feedlots, with an average of 181 steers per pen (Table 1). The feedlots were both located in southern Alberta and were separated by a distance of $62 \mathrm{~km}$. Steers were sampled twice: at entry to the feedlot during the months of May through October, 2007 and prior to shipment to slaughter during the months of September through December, 2007.

The animal care committee at the Lethbridge Research Centre did not evaluate studies done under commercial conditions until after publication in 2009 of revised Canadian Council of Animal Care guidelines on the the care and use of farm animals in research, teaching and testing. Therefore, this study was exempt from requiring ethical approval. However, anything more than a minimally invasive study would not have been acceptable to our commercial collaborators.

Fecal grab and perineal hide swab $\left(100 \mathrm{~cm}^{2}\right.$ area around the anus in the center of the perineum) samples were simultaneously obtained from each steer. Fecal samples were obtained by rectal palpation using a clean glove for each animal. Feces were placed in Whirl-Pak ${ }^{\circledR}$ bags and transported to the laboratory on ice. Perineal swab samples (PS) were obtained using a sterile SpongeSicle ${ }^{\circledR}$ hydrated with $25 \mathrm{~mL}$ of PBS with a new SpongeSicle $^{\circledR}$ used for each animal. Each SpongeSicle ${ }^{\circledR}$ was placed in a separate Whirl-Pak ${ }^{\circledR}$ bag along with $45 \mathrm{~mL}$ of modified E. coli broth with $20 \mathrm{mg} / \mathrm{L}$ novobiocin (mEC-nov) and transported to the laboratory at ambient temperature. All samples were delivered to the laboratory for analysis within a period of $12 \mathrm{~h}$ and refrigerated at $5^{\circ} \mathrm{C}$ until completion of $E$. coli $\mathrm{O} 157: \mathrm{H} 7$ detection and enumeration.

\section{Escherichia coli 0157:H7 Detection}

Bags of feces were manually blended prior to subsampling and $1 \mathrm{~g}$ of feces was added to $9 \mathrm{~mL}$ of mECnov and incubated at $37^{\circ} \mathrm{C}$ for $6 \mathrm{~h}$. Perineal swab samples were incubated in the original transport media for $18 \mathrm{~h}$ at $37^{\circ} \mathrm{C}$. After enrichment, a $1 \mathrm{~mL}$ aliquot of each sample type (fecal grab and PS) was subjected to immunomagnetic separation (IMS) using Dynabeads anti-O157 and a PickPen ${ }^{\circledR}$ magnetic particle separation device as per manufacturers' instructions. Fifty- $\mu \mathrm{L}$ of the bead-bacteria mixture was plated onto sorbitol MacConkey agar supplemented with $2.5 \mathrm{mg} / \mathrm{L}$ potassium tellurite and $0.05 \mathrm{mg} / \mathrm{L}$ cefixime (CT-SMAC) and plates were incubated for $16 \mathrm{~h}$ at $37^{\circ} \mathrm{C}$. Up to 3 sorbitol negative (clear) colonies per plate were subjected to agglutination using an E. coli O157 latex kit. One isolate per sample was further subjected to multiplex PCR assays for the detection of the stx 1 , st $x 2$, eaeA, and flicC (H7) genes and isolates with $e a e A, f l i c C$ and either or both of $s t x 1$ and stx 2 were confirmed as E. coli $\mathrm{O} 157: \mathrm{H} 7$ [37].

\section{Escherichia coli 0157 Enumeration}

Fecal grab samples that were positive for E. coli $\mathrm{O} 157$ were serially diluted ( $1 \mathrm{~g}$ of feces in $9 \mathrm{~mL}$ of mEC-nov) and $100 \mu \mathrm{L}$ of the $10^{-2}$ and $10^{-3}$ dilutions were plated in duplicate onto CT-SMAC. The CT-SMAC plates were incubated for $16 \mathrm{~h}$ at $37^{\circ} \mathrm{C}$. Up to 5 sorbitol-negative (clear) colonies per plate were subjected to agglutination using an E. coli O157 latex kit. Sorbitol-negative colonies were counted on each duplicate plate, dilution calculations were performed, adjustments for the proportion of positive agglutinations out of 5 were made, and counts were recorded in CFU/g. Super-shedders were defined as cattle that had at least $10^{4} \mathrm{CFU}$ E. coli $\mathrm{O} 157: \mathrm{H} 7 / \mathrm{g}$ feces, while low-shedders had $<10^{4} \mathrm{CFU} / \mathrm{g}$ feces. 


\section{Pulsed-field gel electrophoresis}

Isolates confirmed as E. coli O157:H7 from fecal grabs of super-shedders $(\mathrm{n}=162)$, PS of super-shedders $(\mathrm{n}=137)$ and fecal grabs of low-shedder pen mates $(n=496)$ were sub-typed by PFGE using $\mathrm{XbaI}$ restriction according to the standard 1-d protocol [38]. Isolates from low-shedder PS $(n=1023)$ were collected but excluded from analysis due to time and labor constraints. One isolate of E. coli O157:H7 from each positive sample was typed by PFGE using a CHEF DR II electrophoresis unit (Bio-Rad Laboratories, Mississauga, ON, Canada). Banding patterns were viewed with UV illumination and photographed using the Speedlight Platinum Gel Documentation System (Bio-Rad, Mississauga, $\mathrm{ON})$.

\section{Antimicrobial resistance testing}

Isolates $(n=474)$ were tested for resistance to 11 antimicrobials using anti-microbial disk susceptibility tests [39]. Eleven antibiotic discs were applied using a 12-place BBL Sensi-Disc ${ }^{\mathrm{Tm}}$ disc dispenser (VWR, Intl., Edmonton, AB.) The antimicrobials tested included enrofloxacin $(5 \mu \mathrm{g})$, streptomycin $(10 \mu \mathrm{g})$, amoxicillin/clavulanate $(20 / 10 \mu \mathrm{g})$, ceftiofur $(30 \mu \mathrm{g})$, ampicillin $(10 \mu \mathrm{g})$, sulphmethoxazole/ trimethoprim $(23.75 / 1.25 \mu \mathrm{g})$, ceftazadime $(30 \mu \mathrm{g})$, oxytetracycline $(30 \mu \mathrm{g})$, neomycin $(30 \mu \mathrm{g})$, florfenicol $(30 \mu \mathrm{g})$ and sulfasoxazole $(0.25 \mu \mathrm{g})$. Escherichia coli ATCC strain 25922 and Enterococcus faecalis ATCC 29212 were used as controls in accordance with Clinical Laboratory Standards Institute Guidelines [39]. Zone diameters were measured after $18 \mathrm{~h}$ incubation at $37^{\circ} \mathrm{C}$ using a BIO$\mathrm{MIC}^{\circledR}$ V3 digital imaging system and software (Giles Scientific Inc., Santa Barbara, CA).

\section{Statistical analyses}

Pulse-field gel electrophoresis patterns in the digital images were classed as unique or grouped into restriction endonuclease digestion pattern clusters (REPC; 90\% or greater similarity) using Dice similarity coefficients, unweighted pair group methods arithmetic average algorithm, $1 \%$ position tolerance and $0.5 \%$ optimization (BioNumerics 6.5, Applied Maths BVBA, Sin-Martens-Latem, Belgium). Within- and between-group similarities of PFGE profiles for super- and low-shedder isolates within and across feedlot pens were tested using the Dimensioning Techniques package of BioNumerics. For these analyses, binary character profiles using the band-matching option were created after clustering using Dice coefficients. Group similarity was then evaluated using bootstrapping analyses $(\mathrm{n}=1000)$, with significant differences reported at $P<0.05$. Within a pen, similarity of a group (super-shedder fecal isolates, super-shedder perineal swab, or low-shedder fecal isolates) was compared to that of random samples from all isolates in the pen as part of the bootstrapping analysis to determine if similarity among samples in a group was greater than that expected by chance. Membership in REPC A as compared to all other REPC and data generated from antimicrobial resistance profiles of super- and low-shedder fecal isolates were compared using a logit link function and binomial distribution within the GLIMMIX procedure of SAS (SAS 9.1; Cary, NC, USA), with shedding status (super- or lowshedder) and sampling $[1,2]$ as the independent variables, and feedlot pen modeled as a random intercept, with signficiant differences at $P<0.05$ and REML used to estimate the variance component.

\section{Additional files}

Additional file 1: Figure 1. Dendrogram of restriction endonuclease clusters (REPC) from sampling 1, showing REPC shared with sampling 2 (A through E). REPC exlusive to sampling 1 are not labeled.

Additional file 2: Figure 2. Dendrogram of restriction endonuclease clusters (REPC) from sampling 2, showing REPC shared with sampling 1 (A through E).

\section{Competing interests}

The authors declare that they have no competing interests.

\section{Authors' contributions}

CA analysed data using the BioNumerics program. KS performed other statistical analyses, participated in study design and drafted the manuscript. TM contributed to study design and critically reviewed the drafted manuscript. All authors read and approved the final manuscript.

\section{Acknowledgements}

This work was supported by the Food Safety Initiative of Alberta Agriculture and Rural Development. Many thanks to Homayoun Zahiroddini, Geoff Wallins and Jenilee Peters of the Beef Microbiology laboratory of Alberta Agriculture and Rural Development, Lethbridge for the years of technical work required to make this study possible.

\section{Author details}

${ }^{1}$ Alberta Agriculture and Rural Development, Agriculture Centre, 100-5401 1st Ave, S, Lethbridge, AB T1J 4 V6, Canada. ${ }^{2}$ Agriculture and Agri-Food Canada, Lethbridge Research Centre, Lethbridge, AB T1J 4B, Canada.

Received: 22 December 2011 Accepted: 24 September 2012 Published: 26 September 2012

\section{References}

1. Matthews L, McKendrick IJ, Ternet H, Gunn GJ, Synge B, Woolhouse MEJ: Super-shedding cattle and the transmission dynamics of Escherichia coli 0157. Epidemiol Infect 2006, 134:131-142.

2. Carlson BA, Nightingale KK, Mason GL, Ruby JR, Choat WT, Loneragan GH, Smith GC, Sofos JN, Belk KE: Escherichia coli 0157:H7 strains that persist in feedlot cattle are genetically related and demonstrate and enhanced ability to adhere to intestinal epithelial cells. Appl Environ Microbio/ 2009, 75:5927-5937.

3. Stephens TP, McAllister TA, Stanford K: Perineal swabs reveal the effect of super shedders on the transmission of Escherichia coli $0157 \mathrm{H} 7$ in commercial feedlots. J Anim Sci 2009, 87:4151-4160.

4. Chase-Topping M, Gall D, Low C, Matthews L, Woolhouse M: Supershedding and the link between human infection and livestock carriage of Escherichia coli 0157. Nat Rev Micro 2008, 6:904-912.

5. Omisakin F, MacRae M, Odgen ID, Strachan NJC: Concentration and prevalence of Escherichia coli 0157 in cattle feces at slaughter. Appl Environ Microbiol 2003, 69:2444-2447.

6. Robinson SE, Brown PE, Wright EJ, Hart CA, French NP: Quantifying withinand between-animal variation and uncertainty associated with counts of 
Escherichia coli 0157 occurring in naturally infected cattle faeces. J R Soc Interface 2009, 6:169-177.

7. Ferens WA, Hovde CJ: Escherichia coli 0157:H7: animal reservoir and sources of human infection. Foodborne Path Dis 2011, 8:465-487.

8. Cobbold RN, Hancock DD, Rice DH, Berg J, Stillborn R, Hovde CJ, Besser TE: Rectoanal junction colonization of feedlot cattle by Escherichia coli 0157: $\mathrm{H} 7$ and its association with supershedders and excretion dynamics. App/ Environ Microbiol 2007, 73:1563-1568.

9. Stanford K, Stephens TP, McAllister TA: Use of model super-shedders to define the role of pen floor and hide contamination in the transmission of Escherichia coli O157:H7. J Anim Sci 2011, 89:237-244.

10. Fox JT, Renter DG, Sanderson MW, Nutsch AL, Shi X, Nagaraja TG: Associations between the presence and magnitude of Escherichia coli 0157 in feces at harvest and contamination of pre-intervention beef carcasses. J Food Protect. 2008, 71:1761-1767.

11. Jacob ME, Renter DG, Nagaraja TG: Animal and truckload-level associations between Escherichia coli 0157:H7 in feces and on hides at harvest and contamination of pre-evisceration beef carcasses. J Food Protect 2010, 73:1030-1037.

12. Avery SM, Lievana E, Hutchinson ML, Buncic S: Pulsed-field gel electrophoresis of related Escherichia coli 0157 isolates associated with beef cattle and comparison with unrelated isolates from animals, meats and humans. Int J Food Microbiol 2004, 92:161-169.

13. Dodd CC, Renter DG, Fox JT, Shi X, Sanderson MW, Nagaraja TG: Genetic relatedness of Escherichia coli 0157 isolates from cattle feces and preintervention beef carcasses. Foodborne Path Dis 2010, 7:357-365.

14. Sargeant JM, Shi X, Sanderson MW, Renter DG, Nagaraja TG: Pulsed-field gel electrophoresis patterns of Escherichia coli $\mathrm{O} 157$ isolates from Kansas feedlots. Foodborne Path Dis 2006, 3:251-258.

15. Lefebvre B, Diarra MS, Giguere K, Roy G, Michaud S, Malouin F: Antibiotic resistance and hypermutability of Escherichia coli from feedlot cattle treated with growth-promoting agents. J Food Protect 2005, 68:24112419.

16. Van Donkersgoed J, Berg J, Potter A, Hancock D, Besser T, Rice D, LeJeune J, Klashinsky S: Environmental sources and transmission of Escherichia coli 0157 in feed lot cattle. Can Vet J 2001, 42:714-720.

17. Stanford K, Bach SJ, Marx TH, Jones S, Hansen JR, Wallins GL, Zahiroddini H, McAllister TA: Monitoring Escherichia coli 0157:H7 in inoculated and naturally infected feedlot cattle and their environment. J Food Protect 2005, 68:26-33.

18. Matthews L, Low JC, Gally DL, Pearce MC, Mellor DJ, Heesterbeek JAP, Chase-Topping M, Naylor SW, Shaw DJ, Reid J, Woolhouse MEJ: Heterogenous shedding of Escherichia coli 0157 in cattle and its implications for control. Proc Natl Acad Sci 2006, 103:547-552.

19. Tenover FC, Arbeit RD, Goering RV, Mickelsen PA, Murray BE, Pershing DH, Swaminathan B: Interpreting chromosomal DNA restriction patterns produced by pulsed-field gel electrophoresis: criteria for bacterial strain typing. J Clin Microbiol 1995, 33:2233-2239.

20. Vali L, Hamouda A, Pearce MC, Knight HI, Evans J, Amyes SGB: Detection of genetic diversity by pulsed-field gel electrophoresis among Escherichia coli 0157 isolated from bovine faecal samples by immunomagnetic separation technique. Lett Appl Microbiol 2007, 44:19-23.

21. Brun $E_{1}$, Holstad $G$, Kruse $H$, Jarp H: Within-sample and between-sample variation of antimicrobial resistance in fecal Escherichia coli isolates from pigs. Microb Drug Resist 2002, 8:385-391.

22. Vali L, Wisely KA, Pearce MC, Turner EJ, Knight HI, Smith AW, Amyes SGB: High-level genotypic variation and antibiotic sensitivity among Escherichia coli 0157 strains isolated from two Scottish beef cattle farms. Appl Environ Microbiol 2004, 70:5947-5954

23. Prendergast DM, Lendrum L, Pearce R, Ball C, McLernon J, O'Grady D, Scott L, Fanning S, Egan J, Guitierrez M: Verocytotoxigenic Escherichia coli 0157 in beef and sheep abattoirs in Ireland and characterisation of isolates by pulsed-field gel electrophoresis and multi-locus variable number of tandem repeat analysis. Int J Food Microbiol 2011, 144:519-527.

24. Rice DH, McMenamin KM, Prichett LC, Hancock DD, Besser TE: Genetic subtyping of Escherichia coli 0157 isolates from 41 pacific northwest USA cattle farms. Epidemiol Infect 1999, 122:479-484.

25. Arthur TA, Bosilevac JM, Britchta-Harhay DM, Guerin MN, Kalchayanand N, Shackelford SD, Wheeler TL, Koohmaraie M: Transportation and lairage environment effects on prevalence, numbers and diversity of Escherichia coli 0157:H7 on hides and carcasses of beef cattle at processing. J Food Protect 2007, 70:280-286.

26. Stanford K, Croy D, Bach SJ, Wallins GL, Zahiroddini H, McAllister TA: Ecology of Escherichia coli 0157:H7 in commercial dairies in southern Alberta. J Dairy Sci 2005, 88:4441-4451.

27. Childs KD, Simpson CA, Warren-Serna W, Bellenger G, Centrella B, Bowling RA, Ruby J, Stefanek J, Vote DJ, Choat T, Scanga JA, Sofos JN, Smith GC, Belk KE: Molecular characterization of Escherichia coli O157:H7 hide contamination routes: feedlot to harvest. J Food Protect. 2006, 69:1240-1247.

28. Cooley MB, Carychao D, Nguyen K, Whitehand L, Mandrell R: Effects of environmental stress on stability of tandem repeats in Escherichia coli 0157:H7. Appl Environ Microbiol 2010, 76:3398-3400.

29. Avery SM, Buncic S: Escherichia coli 0157 diversity with respect to survival during drying on concrete. J Food Protect 2003, 66:780-786.

30. McGee P, Scott L, Sheridan JJ, Earley B, Leonard N: Horizontal transmission of Escherichia coli 0157:H7 during cattle housing. J Food Prot 2004, 67:2651-2656

31. Rao S, Van Donkersgoed J, Bohaychuk V, Besser T, Song X, Wagner B, Hancock D, Renter D, Dargatz D, Morley PS: Antimicrobial drug use and antimicrobial resistance in enteric bacteria among cattle from Alberta feedlots. Foodborne Path Dis 2010, 7:449-457.

32. Alexander TW, Inglis GD, Yanke $L$, Topp E, Read RR, Reuter T, McAllister TA: Farm-to-fork characterization of Escherichia coli associated with feedlot cattle with a known history of antimicrobial use. Int J Food Microbiol 2010, 137:40-48.

33. Aslam M, Stanford K, McAllister TA: Characterization of antimicrobial resistance and seasonal prevalence of Escherichia coli 0157:H7 recovered from commercial feedlots in Alberta Canada. Letts Appl Micro 2010, 50:320-326

34. Sherley M, Gordon DM, Collignon PJ: Evolution of multi-resistance plasmids in Australian clinical isolates of Escherichia coli. Microbiol 2004, 150:1539-1546.

35. Singer RS, Ward MP, Maldonado G: Can landscape ecology untangle the complexity of antibiotic resistance? Nat Rev Microbiol 2006, 4:943-952.

36. Smith MG, Jordan D, Chapman TA, Chin JJC, Barton MD, Do TN, Fahy VA, Fairbrother JM, Trott DJ: Antimicrobial resistance and virulence gene profiles in multi-drug resistant enterotoxigenic Escherichia coli isolated from pigs with post-weaning diarrhoea. Vet Microbiol 2010, 145:299-307.

37. Gannon VP, D'Souza S, Graham T, King RK: Specific identification of Escherichia coli 0157:H7 using multiplex PCR assay. Adv Exp Med Biol 1997, 412:81-82.

38. Ribot EM, Fair MA, Gautom R, Cameron DN, Hunter SB, Swaminathan B, Barrett TJ: Standardization of pulsed-field gel electrophoresis protocols for the subtyping of Escherichia coli 0157:H7, Salmonella and Shigella for PulseNet. Foodborne Path Dis 2006, 3:59-66. Available online: http://www. cdc.gov/pulsenet/protocols.htm. Accessed June 24, 2011.

39. Clinical and Laboratory Standards Institute: Performance standards for antimicrobial disk susceptibility tests; approved standards - Ninth ed.; 2006

\section{doi:10.1186/1746-6148-8-178}

Cite this article as: Stanford et al:: Genetic diversity and antimicrobial resistance among isolates of Escherichia coli 0157: $\mathrm{H} 7$ from feces and hides of super-shedders and low-shedding pen-mates in two commercial beef feedlots. BMC Veterinary Research 2012 8:178.

\section{Submit your next manuscript to BioMed Central and take full advantage of:}

- Convenient online submission

- Thorough peer review

- No space constraints or color figure charges

- Immediate publication on acceptance

- Inclusion in PubMed, CAS, Scopus and Google Scholar

- Research which is freely available for redistribution 